\title{
Tratamento de Resíduos Gerados em Laboratórios de Polímeros: Um Caso bem Sucedido de Parceria Universidade-Empresa
}

\author{
Elen V. Pacheco, Carlos A. Hemais \\ Grupo de Gestão Tecnológica, IMA, UFRJ \\ Geraldo A. T. Fontoura, Fernando A. Rodrigues \\ Bayer S.A.
}

Resumo: É relatada a bem sucedida experiência de colaboração entre uma instituição de pesquisa, o IMA, e uma empresa privada, a Bayer, que teve por objetivo dar uma solução definitiva para o problema de descarte de resíduos perigosos dos laboratórios de pesquisa em polímeros. Após quase oito anos de atividades, podese considerar que o programa de coleta e incineração de resíduos clorados e não-clorados tem sido bem sucedido.

Palavras-chave: Parceria universidade-empresa, coleta de resíduos de laboratório, meio ambiente.

\section{A Treatment of Residue from Polymer Laboratories: A Successful Case of University and Private Company Partnership}

Abstract: This paper reports on a successful experience of interaction between a research institution, IMA, and a private company, Bayer. The aim of this interaction was to give a final solution to the problem of discarding hazardous residues from polymer research laboratories. After almost eight years of activity, the program of segregation and incineration of chlorinated and non-chlorinated residues is a real success.

Keywords: University-firm partnership, laboratory residue collection, environment.

\section{Introdução}

Tem-se escrito à exaustão sobre a preocupação das nações com o meio ambiente. Por exemplo, nos dias de hoje estão em pauta assuntos como o Protocolo de Kioto sobre a redução de emissões de gases e o debate sobre a modesta proposta norte-americana de cumprimento das recomendações daquele protocolo. Notícias têm revelado diariamente, também, o alto grau de poluição dos mares, grande parte motivada pelas águas dos rios que neles desembocam ${ }^{[1]}$.

Muitas fontes de poluição existem e, que passam despercebidas até de órgãos governamentais de defesa ambiental. E, por pequenas que possam ser essas fontes, grandes males podem causar ao meio ambiente ao longo do tempo. Estamos falando, por exemplo, de resíduos gerados em laboratórios de pesquisa, resultantes de experimentos, análises, subprodutos de reações químicas e de aulas práticas. Estamos falando mais especificamente de resíduos gerados em laboratórios de pesquisa na área de polímeros, que, vertidos no meio ambiente sem quaisquer tratamentos, podem gerar, ao longo do tempo, danos irrecuperáveis à natureza ${ }^{[2]}$.

O presente artigo apresenta os resultados de um bem sucedido programa de parceria entre uma instituição de pesquisa universitária, o IMA/UFRJ, e uma empresa privada, a Bayer, visando resolver eficientemente o problema de descarte dos resíduos tóxicos dos laboratórios de pesquisa e, com isso, contribuir

Autor para correspondência: Carlos A. Hemais, Grupo de Gestão Tecnológica, IMA/UFRJ, Caixa Postal 68545, CEP: 21945-970, Rio de Janeiro, RJ. E-mail: hemais@ima.ufr.br 
para o esforço coletivo de preservação de nosso meio ambiente.

\section{A Universidade e a educação ambiental}

A maior função social da universidade é a educação. E, dentro de seu exercício de difusão de conhecimentos, está a função de conscientização de seus alunos sobre o meio ambiente, visando educá-los para que levem suas experiências nessa área para suas vidas profissionais e mesmo para suas casas. Além das aulas normais ministradas nas universidades, aí são desenvolvidas pesquisas científicas e tecnológicas, gerando subprodutos, principalmente no ramo químico e da saúde, que devem ser tratados. Algumas instituições já fazem o trabalho de gerenciamento desses resíduos ou tentam minimizar a toxicidade de seus descartes, porém poucas se preocupam com seu destino final[ ${ }^{[2-11]}$.

As instituições de ensino que não gerenciam seus resíduos estão perpetuando em seus alunos, funcionários e professores a prática errada de descartar seus resíduos sem tratamento ou disposição adequados. Os alunos, cidadãos e futuros profissionais, por este exemplo, poderão vir a descartar os resíduos da empresa onde trabalham incorretamente ou a jogar seu lixo domiciliar nas ruas, nos rios, nas baías, nas encostas. Alguns programas estão sendo desenvolvidos dentro de laboratórios, com o objetivo de reduzir a toxidade dos resíduos; porém, o descarte final adequado é difícil, uma vez que, no Brasil, o lixo urbano é destinado, em sua quase totalidade, a terrenos a céu aberto $^{[2-11]}$.

Entre as iniciativas de minimização de resíduos em instituições governamentais que merecem destaque estão os trabalhos de Jardim ${ }^{[6]} \mathrm{em}$ prol da educação ambiental em laboratórios universitários. A metodologia seguida pelo autor para a gestão dos resíduos obedece a uma hierarquia de ações, que vão das mais desejáveis até as menos desejáveis, quais sejam: redução da produção de resíduos na fonte; reutilização e recuperação de resíduos; redução da toxicidade e volume e, por último, tratamento ou disposição do resíduo de forma ecologicamente correta.

Os resíduos produzidos nas universidades geram problemas para todas as instituições. Por exemplo, Tonocchi ${ }^{[12]}$ nos apresenta o caso da Unicamp, em São Paulo, que não tem espaço físico para guardar os resíduos perigosos, provenientes de suas pesquisas, ensino e atividades de extensão, produzidos desde a criação da universidade, há 35 anos. Estima-se que a produção desses resíduos seja de 15 toneladas por ano. Na Unicamp, pelo menos, os resíduos não são descartados aleatoriamente; eles são armazenados temporariamente enquanto esperam por uma destinação final. Entretanto, observa-se sempre o risco de acidentes nesses locais de armazenamento temporário de resíduos, em função da deterioração dos mesmos e de suas embalagens. Outras instituições, porém, jogam em seus esgotos os resíduos perigosos, sem quaisquer tratamentos ${ }^{[12]}$.

\section{Opções para uma gestão ambiental ecologicamente correta}

Os resíduos líquidos dos laboratórios são classificados, em sua maioria, como resíduos perigosos, cujas opções de destinos devem ser a reciclagem, o co-processamento ou a incineração.

Reciclar resíduos é transformá-los em produtos com valor agregado. Do ponto de vista ambiental, essa prática é muito atraente, pois diminui a quantidade de resíduos lançados no meio ambiente, além de contribuir para a conservação dos recursos naturais, minimizando a utilização de recursos nãorenováveis. A reciclagem, porém, depende do custo de transporte e da quantidade de resíduos disponíveis para que o reprocessamento se torne viável economicamente. Devido à crescente conscientização social, a reciclagem de resíduos tende a se tornar cada vez mais comum. Sua prática requer empresas e profissionais habilitados, bem como tecnologias adequadas, capazes de assegurar qualidade e segurança em sistemas cada vez mais complexos. Alguns laboratórios de pesquisa reciclam parte de seus próprios resíduos, através de destilação e da reutilização. Porém, chega-se a um ponto em que é inviável tecnicamente alguns desses procedimentos. Por outro lado, a reciclagem não deve ser encarada como uma panacéia que irá resolver todos os problemas ambientais no contexto dos resíduos perigosos.

O co-processamento em fornos de cimento se constitui em uma alternativa para a destruição térmica com o aproveitamento energético e/ou de massa dos resíduos, que passam, dessa forma, a serem utilizados como matérias-primas e fontes de energia no processo de fabricação de cimento. Outrossim, nos fornos de cimento, tendo em vista as enormes vazões de 
emissões gasosas envolvidas no processo, é economicamente inviável o processamento de resíduos críticos do ponto de vista da poluição atmosférica. Em muitos países, inclusive no Brasil (há uma resolução do CONAMA específica tratando a matéria), estas restrições já são regulamentadas através de instrumentos legais. Boa parte dos solventes utilizados em laboratório são clorados, inviabilizando, por força legal, a utilização do co-processamento ${ }^{[13]}$.

A incineração consiste em um processo de oxidação térmica. As temperaturas do processo variam de 800 a $1300{ }^{\circ} \mathrm{C}$. Nessas temperaturas e com excesso de oxigênio (atmosferas fortemente oxidantes) ocorre a destruição térmica dos resíduos orgânicos, com a conseqüente redução de volume e de toxicidade do material incinerado. Em geral, a incineração não é usada com o intuito único de redução de volume, pois, se comparada com outros processos, ela se torna economicamente inviável, quando adotada apenas para essa finalidade. A incineração está associada à eliminação de contaminantes altamente persistentes, tóxicos e inflamáveis. Estão incluídos aqui solventes e óleos não passíveis de recuperação, defensivos agrícolas e produtos farmacêuticos. A NBR $n^{\circ} 11.175$, que regula a incineração de resíduos perigosos, define os padrões de emissão de $\mathrm{HCl}, \mathrm{HF}, \mathrm{CO}, \mathrm{SO}_{2}, \mathrm{NO}_{2} \mathrm{e}$ materiais particulados e os requisitos de operação, obriga o monitoramente contínuo e orienta sobre o chamado teste de queima ${ }^{[14]}$.

As unidades de incineração variam desde instalações pequenas, projetadas e dimensionadas para um resíduo específico, até grandes instalações de propósitos múltiplos, para incinerar resíduos de diversas fontes. Estas instalações requerem equipamentos adicionais de controle de poluição do ar, com a conseqüente demanda de maiores investimentos. Além disso, precisam principalmente ser credenciadas pelos órgãos ambientais estaduais ${ }^{[14]}$.

Cabe destacar que estamos nos referindo aos sistemas de incineração com ênfase nos resíduos, aqueles nos quais todos os cuidados são tomados para garantir as condições ideais de queima e para tratar os gases da combustão que são gerados no processo. A prioridade, quando se abordam os sistemas de incineração com ênfase nos resíduos não é a conservação de energia e nem tão pouco a reciclagem de materiais. A ênfase é eliminar resíduos perigosos que, de outra sorte, poderiam causar danos ao meio ambiente ou à saúde das populações.

\section{0 problema}

O Instituto de Macromoléculas Professora Eloisa Mano da Universidade Federal do Rio de Janeiro (IMA/UFRJ) é uma instituição formadora de profissionais pós-graduados na área de ciência e tecnologia de polímeros, ou seja, na área de plásticos, borrachas, tintas, vernizes e fibras. Tendo como objetivo realizar pesquisas no campo macromolecular, hoje estão em atividades nos laboratórios da instituição cerca de 100 pessoas, entre professores, pesquisadores, alunos de doutorado, mestrado, especialização e de iniciação científica, além de técnicos.

Em 2001, o IMA produziu 18 trabalhos de doutorado e mestrado, bem como publicou cerca de uma centena de trabalhos. As pesquisas são realizadas nas diversas áreas de polímeros, tais como síntese e caracterização de macromoléculas, resinas de trocaiônica, macromoléculas para a indústria de petróleo, polímeros naturais, biopolímeros, borrachas, polimerização utilizando catalisadores Ziegler-Natta, metalocênicos e não-metalocênicos, tecnologia de polímeros, degradação de polímeros, reciclagem de plásticos e gerenciamento de resíduos, entre outras.

O IMA, como qualquer outro centro de pesquisa, gera resíduos líquidos que podem ser classificados em orgânicos clorados, não-clorados e hidrossolúveis; e resíduos sólidos, tais como vidros de reagentes, vidros de laboratório quebrados, plásticos processados, borrachas, papel de filtro, etc. As pesquisas que lidam com síntese são as que mais geram resíduos líquidos. As que trabalham com tecnologia geram, normalmente, resíduos sólidos. Normalmente os trabalhos desenvolvidos nessa última envolvem processamentos tais como extrusão, injeção e prensagem de plásticos e borrachas, gerando como resíduos, borras e restos de corpos de prova de plástico e borracha. Esses resíduos de polímeros são os que, normalmente, são gerados na confecção de produtos acabados e não constituem perigo seu descarte junto aos resíduos urbanos comuns.

Os produtos orgânicos clorados mais gerados nos laboratórios do IMA são dicloroetano, tetracloreto de carbono, clorofórmio e diclorometano. Em geral, os resíduos clorados são misturados com os não-clorados (como etanol, metanol, tolueno e acetona), aumentando o seu poder calorífico. Quanto aos não-clorados, os mais comuns são o tolueno $(\sim 15 \%)$, o metanol $(\sim 15 \%)$, o etanol $(\sim 10 \%)$, a acetona $(\sim 5 \%)$ e o 
benzeno, que representam quase $50 \%$ dos resíduos orgânicos não-clorados do Instituto. Esses valores numéricos são relativos, pois a pesquisa é dinâmica e existe uma evolução nos estudos e modificação nos experimentos e produtos utilizados.

Até 1996, o equivalente a 100 litros por mês de resíduos líquidos orgânicos, subprodutos das reações químicas, eram vertidos diretamente nas pias dos laboratórios. Com o passar dos anos, os canos de esgotos dos laboratórios, tanto os de PVC quanto os de ferro fundido, foram profundamente atacados pelos produtos químicos, fazendo com que grande parte deles apresentasse furos e vazasse produtos tóxicos diretamente no subsolo do prédio, que não é revestido. Como o instituto foi construído em terreno de aterro, a uma curta distância do mar, a rápida permeação dos resíduos tóxicos pelo subsolo ocasionava a contaminação do lençol freático e, em última instância, da Baía de Guanabara. A atmosfera do subsolo era altamente corrosiva e propiciava a destruição de outros encanamentos de ferro galvanizado, destinados a água, gás butano, nitrogênio, eletricidade e ar comprimido, como mostrado na Figura 1, colocando em risco, ainda, a segurança das instalações.

Por outro lado, resíduos sólidos e mesmo resíduos líquidos mais perigosos eram enterrados nos terrenos em volta do IMA, fazendo com que percolassem

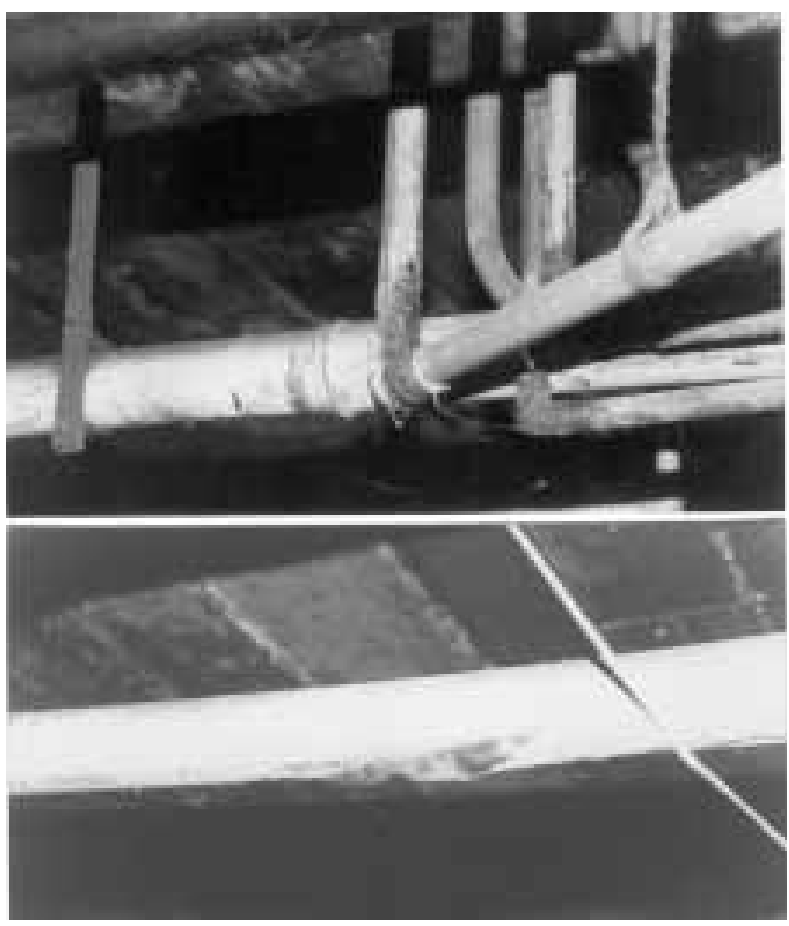

Figura 1. Canos no subsolo do IMA/UFRJ muito facilmente para a Baía de Guanabara, contribuindo para a poluição da mesma. Por aquela época, o governo de Estado do Rio de Janeiro iniciava uma operação de despoluição da baía, o que hoje se constitui no maior conjunto de obras de saneamento básico realizado nos últimos vinte anos no Estado. O programa tinha por objetivo procurar reverter o processo de degradação em que se encontrava a baía e, inclusive, contava para tanto com financiamento de instituições internacionais. O governo colocava como sendo a luta de todos pela salvação da baía. O IMA se sentiu na obrigação de fazer alguma coisa que impedisse que os rejeitos tóxicos atingissem a baía. Partiu-se do pressuposto de que, por menor que fosse a ação, valeria a pena executá-la. E por menor que fosse a quantidade de descartes gerados pelo instituto que atingisse as águas do mar, isso deveria ser impedido. Esta seria, pois, a contribuição do IMA ao programa governamental e deveria ser uma forma de educação ambiental para seus alunos e um exemplo para ser seguido por outras instituições semelhantes.

\section{A busca de solução para o problema de descarte}

Em julho de 1996, sentindo a gravidade do problema, o IMA, através do Grupo de Gestão Tecnológica-GET, iniciou o programa de coleta de resíduos líquidos dos laboratórios. Como toda instituição governamental brasileira, havia no IMA severa limitação orçamentária para qualquer projeto que se pensasse iniciar. O desafio seria criar um programa que resolvesse o problema da instituição de maneira eficiente e que não envolvessem custos adicionais ao já contido orçamento para as pesquisas.

Feita uma pesquisa na Associação Brasileira de Normas Técnicas (ABNT), não foram encontradas normas que pudessem atender às necessidades do IMA. Realizaram-se pesquisas também na Internet. Os resultados obtidos não foram muito úteis para trazer uma solução para o problema. Buscou-se também descobrir a experiência de outras instituições similares no Brasil, porém nada que pudesse nortear o programa do IMA foi descoberto. Decidiu-se, então, criar normas próprias de coleta, baseadas em consultas a especialistas da área ambiental e, acima de tudo, baseadas no bom senso.

Em uma primeira instância, resolveu-se priorizar o que era mais perigoso para os integrantes do instituto e para o meio ambiente. Procurou-se tratar os 
resíduos líquidos orgânicos clorados e não-clorados, e, mais tarde, alguns resíduos sólidos. Assim, foi estabelecida uma rotina para que os resíduos clorados e não-clorados não fossem mais vertidos nas pias. Em primeiro lugar, eles são depositados temporariamente nos laboratórios onde se originam, em recipiente de vidro de 5 litros, após serem cadastrados. O registro do depósito nesses recipientes é feito em fichas de registro, fornecidas a todos os laboratórios. Posteriormente, o conteúdo desses recipientes é esvaziado em tambores especiais de 50 litros, depositados em recinto próprio, protegido das intempéries e localizado fora do prédio. Quando esses tambores ficam cheios, eles são transportados para serem incinerados.

Os resíduos hidrossolúveis (bases, ácidos e sais), também produzidos nos laboratórios, não são coletados, uma vez que contêm grande quantidade de água, não justificando sua incineração. O procedimento aconselhável para o tratamento desse tipo de resíduo é sua neutralização em caixa de decantação, para que possa entrar no sistema de esgoto sem causar danos aos encanamentos ou ao meio ambiente. No momento nada ainda é feito quanto a esses resíduos, mas existe projeto de construção das caixas de decantação no subsolo do IMA, à espera de verba.

Deve-se enfatizar, porém, que o programa só começou após um período de conscientização de todos os professores, pesquisadores, alunos e técnicos sobre a importância do projeto, sobre os danos sofridos pela instituição com os descartes de resíduos através das pias, bem como sobre as vantagens que se esperava obter, tanto em relação ao prédio e ao seu entorno quanto para o meio ambiente em geral. A receptividade de todos foi imediata e houve a concordância geral em participarem do programa. Esse processo de "educação ambiental" ainda é feito através de uma palestra anual, no auditório do IMA, visando atingir aos novos alunos, bem como reforçar o programa junto aos demais pesquisadores. Inspeções periódicas são feitas em todos os laboratórios, visando verificar a implementação dos procedimentos de coleta, dirimir dúvidas dos pesquisadores e fortalecer o vínculo existente entre esses pesquisadores e a preservação ambiental.

\section{A parceria universidade-empresa}

A história de colaboração entre a Bayer e o IMA vem de longa data. Ela se fez através da doação de produtos, bem como da realização de projetos de pesquisa, quando a empresa alemã chegou a patrocinar bolsas para alunos. O IMA, por seu lado, tem sido fornecedor de mão-de-obra altamente especializada para a empresa e diversos elementos treinados nos laboratórios da instituição passaram a integrar a equipe da Bayer. É comum, também, a programação de visita dos alunos do IMA às instalações industriais da Bayer, no município de Belford Roxo, parte integrante do Grande Rio de Janeiro. Assim, existia uma interação periódica entre as duas instituições.

Ao iniciar o programa de coleta de resíduos perigosos no IMA, pensou-se em consultar especialistas no assunto, que pudessem orientar as ações a serem tomadas e discutir uma metodologia que pudesse ser adotada pelo instituto, sem prejudicar o andamento dos trabalhos de pesquisa. A primeira opção escolhida foi a consulta à Área de Meio Ambiente da Bayer S.A., uma vez que: (1) já existia uma interação com a empresa; (2) a área de Meio Ambiente da Bayer era conhecida por sua muito bem sucedida atuação ambiental; e (3) a Bayer mantinha um incinerador rotativo de emissões controladas, credenciado pela Feema, destinado a incinerar produtos de alta toxicidade.

Assim, a orientação recebida da Bayer S.A. quanto à avaliação da coleta e à destinação dos resíduos foi primordial para o início do programa. Em julho de 1996, começou-se a coletar os resíduos, a cadastrálos e a armazená-los. A cada período de 4 meses, aproximadamente, uma quantidade equivalente a 500 litros passou a ser_enviada para incineração na Bayer. Os Gráficos 1 e 2 mostram as quantidades incineradas por ano de resíduos orgânicos clorados e nãoclorados.

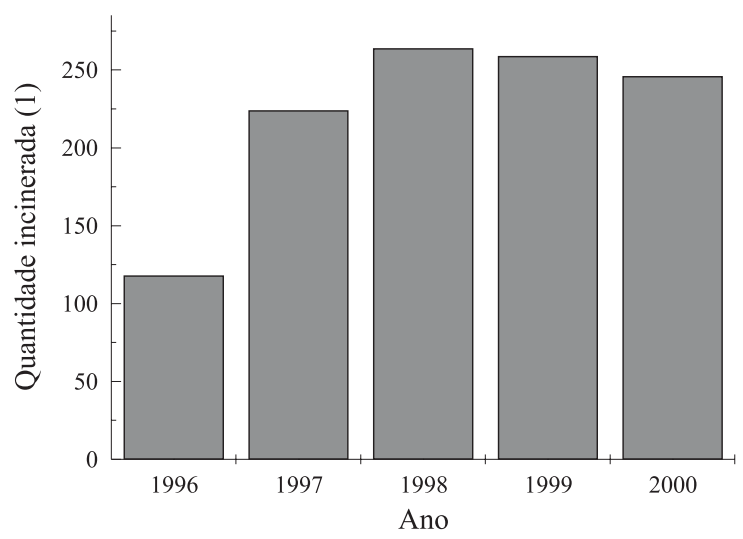

Gráfico 1. Quantidade de resíduos líquidos não-clorados incinerados por ano 


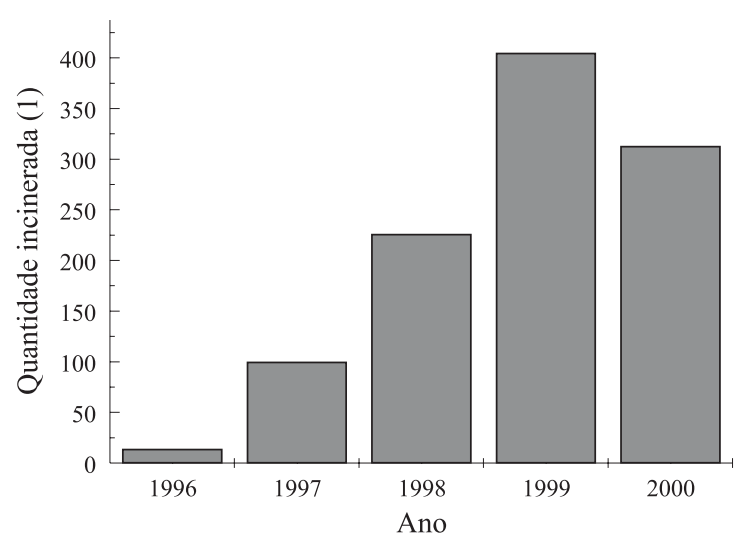

Gráfico 2. Quantidade de resíduos líquidos clorados incinerados por ano.

\section{A incineração na Bayer}

De julho de 1992 a julho de 2001, a Bayer S.A. operou, em seu Complexo Industrial de Belford Roxo, um incinerador rotativo de resíduos sólidos, líquidos e pastosos (Figura 2), com uma capacidade de queima de 3200 toneladas/ ano. Atualmente esta unidade, bem como o aterro industrial, a estação de tratamento de despejos industriais e o laboratório são operados pela Tribel S.A., empresa oriunda de uma joint-venture entre a Bayer S.A. e a Tredi Environment.

Os resíduos sólidos a serem incinerados são acondicionados em bombonas de polietileno ou em cartolas de papelão e introduzidos no forno rotativo através de elevador e pistões. Os resíduos líquidos a serem incinerados são estocados em um tanque fixo ou em containers móveis e são transferidos para os queimadores através de pressão de nitrogênio, sendo atomizados com ar.

$\mathrm{O}$ incinerador de resíduos possui um sistema de combustão composto de um forno rotativo, uma câmara de pós-combustão e três queimadores. $\mathrm{O}$ forno

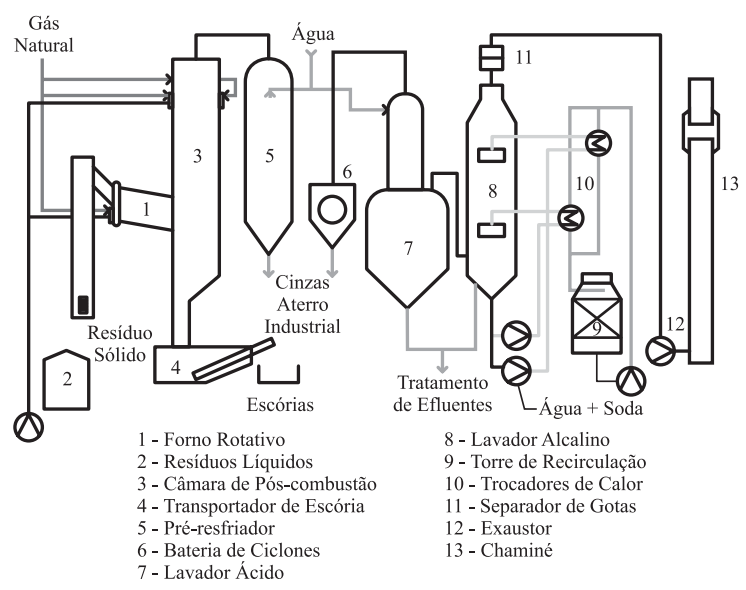

Figura 2. O Incinerador Rotativo da Bayer S.A. rotativo trabalha a uma temperatura de $800-1000{ }^{\circ} \mathrm{C}$ que é mantida através de uma alimentação equilibrada de resíduos líquidos e sólidos e utilizando-se gás natural como combustível auxiliar. Após o forno rotativo, as escórias são retiradas pelo fundo da câmara de pós-combustão e enviadas ao aterro industrial duplamente protegido. Os gases são incinerados a uma temperatura de $1050-1250{ }^{\circ} \mathrm{C}$ na câmara de pós-combustão. Na câmara existem dois queimadores para resíduos líquidos e gás natural, que são responsáveis pela manutenção da temperatura na faixa desejada.

A corrente gasosa de saída da câmara de pós-combustão passa pelo sistema de resfriamento de lavagem dos gases, que é composto por um pré-resfriador (onde os gases são resfriados a $420^{\circ} \mathrm{C}$ ), ciclones, um pós-resfriador (no qual os gases são resfriados a $75^{\circ} \mathrm{C}$ ), um lavador de discos rotativos e um separador de gotículas, antes de ser lançada na atmosfera, a $40{ }^{\circ} \mathrm{C}$, através de uma chaminé. O tratamento dos gases do incinerador rotativo gera cinzas, que são dispostas no aterro industrial, e efluentes líquidos que são tratados na estação de tratamento.

$\mathrm{O}$ incinerador rotativo garante uma eliminação segura e eficiente dos resíduos, atendendo aos mais rígidos padrões de controle ambiental existentes no mundo (destruição superior a 99,999\%).

\section{Coleta de resíduo sólido}

O programa de coleta de resíduos do IMA, progressivamente, passou também a se preocupar com alguns resíduos sólidos gerados na instituição. Dessa forma, os papéis usados são coletados pelos empregados da limpeza, com o intuito de melhorar suas receitas. Os cartuchos de impressoras a jato de tinta, o toner de impressoras a laser $e$ as baterias de telefones celulares são recolhidos e doados a uma organização não-governamental, que cuida de crianças carentes.

Os frascos de vidros foram, por muitos anos, um sério problema para a instituição, pois existia uma grande preocupação com a reutilização indevida desses recipientes, além de não haver mais espaço para seu armazenamento. Comumente, recipientes pós-utilizados eram encontrados com água, o que ajudava na proliferação de vetores. Além disso, poderiam conter resíduos de material inflamável ou explosivo, o que se constituía em um fator de perigo para todo o prédio. 


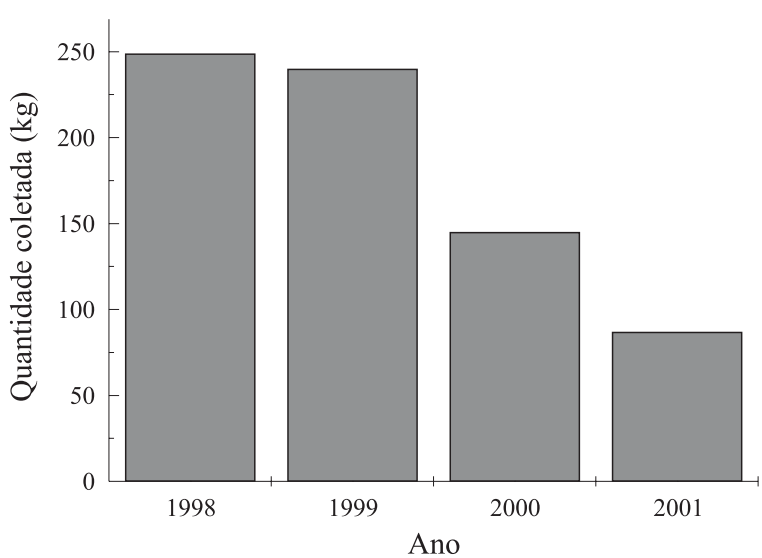

Gráfico 3. Quantidade anual de frascos de vidros coletada no IMA.

Foi feito um sério trabalho de educação dos pesquisadores dentro do instituto e hoje esses frascos de vidros são lavados e secos, suas tampas são retiradas e, posteriormente, os recipientes são separados por diferença de cor em tambores tampados. Periodicamente, um sucateiro recolhe esse material e os leva a uma empresa vidreira para que sejam integrados diretamente no processo produtivo, sendo o material fundido em fornos, a uma temperatura aproximada de $1300^{\circ} \mathrm{C}$. Assim, esse material passou a ser recuperado de forma técnica e ecologicamente correta. As quantidades de vidro coletadas no instituto e enviadas para serem recicladas estão apresentadas no Gráfico 3. Observa-se um declínio acentuado na quantidade de frascos de vidros coletados ao longo dos anos. Isto se deve ao fato de que, nos dois primeiros anos, foram encaminhados para reciclagem todos os frascos de vidros que, por muitos anos, ficaram armazenados no subsolo do IMA. As quantidades de frascos coletados nos anos 2000 e 2001 representam efetivamente a geração anual destes resíduos, pois já não existem mais frascos de vidro armazenados no prédio.

\section{Conclusão}

Após quase oito anos de atividades, pode-se considerar que o programa de coleta e incineração de resíduos clorados e não-clorados tem sido bem sucedido. E pode-se atribuir esse sucesso, primordialmente, a dois fatores: (1) o apoio recebido, tanto individual como coletivamente, de todos os elementos do IMA, que se comprometeram desde o primeiro momento com a realização do programa; e (2) a interação com a Bayer S.A, tanto na fase inicial de orientação e ajuda na ela- boração da metodologia de trabalho, quanto na colocação à disposição do IMA de seu incinerador.

Se por um lado a Bayer incinerou os resíduos gerados pelos estudos e pesquisas do IMA que foram sendo acumulados ao longo dos anos, por outro, o IMA também colaborou com o programa de educação ambiental da empresa. A instituição de ensino ministrou um curso sobre reciclagem de materiais sólidos pós-consumo, bem como participou diversas vezes da "Semana de Meio Ambiente", evento anual organizado pela Bayer em sua sede em Belford Roxo; a participação do IMA se fez através de palestras proferidas e apresentação dos resultados das suas pesquisas referentes à reciclagem de materiais. Naqueles eventos, os funcionários da empresa puderam verificar exemplos práticos de reciclagem de materiais, tais como poliolefinas e PET, e também conheceram o que o IMA, através de seu Grupo de Gestão Tecnológica, fazia na área de gestão ambiental e coleta seletiva.

O programa é uma prova de que a tão propalada integração universidade-empresa, por mais difícil que seja de ser iniciada, deve ser buscada uma vez que ambas as partes podem beneficiar-se com ela. No presente caso, a Bayer incinera os resíduos do IMA e o instituto colabora com a empresa no treinamento de pessoal em temas relacionados a polímeros e a reciclagem de plásticos e de outros materiais.

Hoje as condições de trabalho no IMA melhoraram e o meio ambiente não é mais agredido pelo descarte dos resíduos gerados pelo instituto. Acima de tudo, o IMA está cumprindo sua missão universitária de passar a seus alunos, futuros pesquisadores em empresas e em outras universidades, um legado de respeito ao meio ambiente e de preservação dos recursos naturais.

\section{Referências Bibliográficas}

1. "Protocolo de Kioto" Disponível em www. mct.gov.br. (2002)

2. Pacheco, E. B. \& Hemais, C. A. - "Gerenciamento de resíduos líquidos de laboratório: a experiência do IMA/UFRJ", Revista de Química Industrial, 716, 26-30 (2000).

3. Pacheco, E. B. \& Hemais, C. A. - "Coleta seletiva de resíduos líquidos perigosos dos laboratórios do IMA/UFRJ", Encontro Técnico Reciclagem - Tecnologia \& Negócios, Instituto de 
Macromoléculas/UFRJ, Rio de Janeiro, RJ (1996).

4. Pacheco, E. B. \& Hemais, C. A. "Despoluição ambiental do IMA", Anais do II Encontro Regional de Polímeros, IMA/UFRJ, Rio de Janeiro, RJ, 77 (1998).

5. Pacheco, E. B. \& Hemais, C. A. - "Experiência de coleta seletiva de resíduos de laboratório", Anais do V Congresso Brasileiro de Defesa do Meio Ambiente, Clube de Engenharia, RJ (1998).

6. Jardim, W. F. - "Gerenciamento de resíduos químicos em laboratórios de ensino e pesquisa", Química Nova 21(5), 671-673 (1998).

7. Barbosa, D.; Costa, M. A. S. \& Pacheco, E. B. "Gerenciamento de resíduos dos laboratórios do Instituto de Química da UERJ", 9a Semana de Iniciação Científica, UERJ (2000).

8. Costa, M. A. S.; Pacheco, E. B.; Barbosa, D. \& Pinto, R. N. - "Avaliação de resíduos dos laboratórios de química da UERJ", Anais do XV Congresso Brasileiro de Química, Recife, PE, QMA 375, 82 (2000).

9. Pacheco, E. B. \& Hemais, C. A. - "Experiência de coleta seletiva de resíduos de laboratórios”, Anais do III Encontro Regional de Polímeros, Rio de Janeiro, RJ (2000).

10. Amaral, S. T. et al - "Relato de uma experiência: recuperação e cadastramento de resíduos dos laboratórios de graduação do Instituto de Química da Universidade Federal do Rio Grande do Sul", Química Nova 24(3), 419-423 (2001).

11. Cunha, C. J. - "O programa de gerenciamento dos resíduos laboratoriais do depto. de Química da UFPR”, Química Nova 24(3), 424-427 (2001).

12. Tonocchi, M. - "Unicamp esgota espaço para lixo tóxico", site www.reciclaveis.com.br, (29/8/2001) (2001).

13. Resolução CONAMA (Conselho Nacional do Meio Ambiente) n. 264, de 26/8/99.

14. ABNT (Associação Brasileira de Normas Técnicas) NBR 11.175: "Incineração de resíduos perigosos - padrões de desempenho", Junho/1990.

Recebido: 03/04/02 Aprovado:26/10/02 